Check for updates

Cite this: RSC Adv., 2017, 7, 18696

Received 4th February 2017

Accepted 22nd March 2017

DOI: 10.1039/c7ra01425b

rsc.li/rsc-advances

\section{One-step preparation and application of magnetic sludge-derived biochar on acid orange 7 removal via both adsorption and persulfate based oxidation}

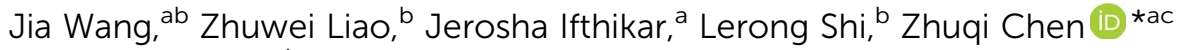 \\ and Zhulei Chen ${ }^{\star b}$
}

\begin{abstract}
Magnetic sludge-derived biochar (MSDBC) was synthetized via a one-step co-precipitation method and conducted as a novel heterogeneous catalyst of persulfate (PS) activation for the oxidative removal of acid orange 7 (AO7). The porous structure and large surface area benefits the enrichment of the pollutant, while abundant $\mathrm{Fe}_{3} \mathrm{O}_{4}$ species and oxygen-containing functional groups promoted the generation of oxidative radicals, thus leading to the remarkable performance of AO7 removal. MSDBC also exhibited good stability with low iron leaching and consistent efficiency in reusability experiments. Radical scavenger experiments and electron paramagnetic resonance studies identified $\mathrm{SO}_{4}{ }^{-{ }^{-}}$and $\mathrm{OH}^{*}$ as the dominant oxidative radicals. The magnetic properties and feasible preparation method of MSDBC guaranteed the stability, which was evidenced in detail by the satisfactory reusability performance and low iron leaching during the degradation process. Distinguished from other PS based advanced oxidation processes, acidic conditions favored $\mathrm{AO} 7$ removal, while two halide irons $\mathrm{Cl}^{-}$and $\mathrm{Br}^{-}$could promote AO7 removal by MSDBC/PS system. The current outcomes demonstrated our approach of converting solid waste into stable, cheap and multifunctional biochar as a feasible resource utilization method, and was highly suggestive to the treatment of both wastewater and sewage sludge.
\end{abstract}

\section{Introduction}

Over the past two decades, persulfate (PS, $\left.E^{0}=2.01 \mathrm{~V}\right)$ based advanced oxidation processes (AOPs) have been studied intensely for organic pollutant removal in soils and water..$^{1,2}$ PS alone showed low efficiency on organic pollutant removal under ambient conditions. ${ }^{3,4}$ Appropriate activation methods should be used to produce more activated sulfate radicals $\left(\mathrm{SO}_{4}{ }^{-}, E^{0}=\right.$ 2.5-3.1 V) ${ }^{2}$ and hydroxyl radicals $\left(\mathrm{OH}^{\circ}, E^{0}=1.9-2.7 \mathrm{~V}\right) .^{5}$ Methods such as thermal-, ${ }^{6}$ ultraviolet (UV) light- ${ }^{7}$ and microwave- ${ }^{8}$ activation needed high energy consumption, and baseactivated systems only showed high efficiency under alkaline conditions. ${ }^{9}$ To overcome the aforementioned drawbacks, novel catalysts have been extensively designed and studied for PS activation. Persulfate can be activated through a one-electron transfer using transition metals such as iron, copper and

${ }^{a}$ Key Laboratory of Material Chemistry for Energy Conversion and Storage, Ministry of Education, Hubei Key Laboratory of Material Chemistry and Service Failure, School of Chemistry and Chemical Engineering, Huazhong University of Science and Technology, Wuhan 430074, P. R. China. E-mail: wangjia910906@163.com; jerosha.ifthikar@ gmail.com; zqchen@hust.edu.cn

${ }^{b}$ Department of Environmental Engineering, School of Environmental Science and Engineering, Huazhong University of Science and Technology, Wuhan 430074, P. R. China.E-mail: liaozhuwei@hust.edu.cn; shilerong@yahoo.com; chenzhulei@263.net ${ }^{c}$ Shenzhen Huazhong University of Science and Technology Research Institute, Shenzhen, P. R. China cobalt etc., among which iron has received considerable attention as a high efficiency, non-toxic, environmentally friendly and cost favored catalyst. ${ }^{10}$ The most famous route of iron-based catalysts is to decompose persulfate by a one-electron transfer from homogeneous $\mathrm{Fe}^{2+}$ (eqn (1)) $)^{11}$ and/or heterogeneous $\mathrm{Fe}(\mathrm{II})$ $(\text { eqn }(2))^{12}$ to persulfate.

$$
\begin{gathered}
\mathrm{Fe}^{2+}+\mathrm{S}_{2} \mathrm{O}_{8}{ }^{2-} \rightarrow \mathrm{Fe}^{3+}+\mathrm{SO}_{4}{ }^{2-}+\mathrm{SO}_{4}{ }^{--} \\
\equiv \mathrm{Fe}(\mathrm{II})+\mathrm{S}_{2} \mathrm{O}_{8}{ }^{2-} \rightarrow \equiv \mathrm{Fe}(\mathrm{III})+\mathrm{SO}_{4}{ }^{2-}+\mathrm{SO}_{4}{ }^{--}
\end{gathered}
$$

Comparing homogeneous $\mathrm{Fe}^{2+},{ }^{13}$ heterogeneous catalysts such as zero valent iron (ZVI), ${ }^{11}$ iron oxides ${ }^{14}$ and bimetallic or tri-metallic iron based catalysts ${ }^{15}$ are more attracted due to vast advantages of heterogeneous reaction process. For instance, for bimetallic or tri-metallic iron based catalysts, on one hand, radicals reactions usually happen on the heterogeneous activated sites of the catalysts which will avoid drawbacks such as iron precipitation under alkaline condition. One the other hand, deposition of additional metal(s) on the surface of iron particles favors slow and sustaining iron corrosion from the catalysts, maintains $\mathrm{SO}_{4}{ }^{--}$concentration at an appropriate level, thus avoids self-quenching of superfluous $\mathrm{SO}_{4}{ }^{\cdot-} \cdot{ }^{-15}$

$\mathrm{Fe}_{3} \mathrm{O}_{4}$ showed relatively high efficiency on persulfate activation for degradation of some organic pollutants..$^{12,14,16}$ In addition, the magnetic properties of $\mathrm{Fe}_{3} \mathrm{O}_{4}$ can facilitate phase 
separation. However, $\mathrm{Fe}_{3} \mathrm{O}_{4}$ particles tend to aggregate because of the strong magnetic interaction, thereby partly diminishing their potency for persulfate activation. ${ }^{17}$ To avoid aggregating of $\mathrm{Fe}_{3} \mathrm{O}_{4}$ particles, appropriate materials were chosen as support. ${ }^{17-20}$ Thus, the chemical and physical property of the support itself become the key issue to manipulate the performance of heterogeneous catalyst in PS based AOPs, and low-cost support with large surface area and stability are eagerly desired.

Biochar is considered as one of the most ideal adsorbents in remediation of aqueous pollutants due to its porous structure and low-price. ${ }^{19}$ Thus, loading magnetic $\mathrm{Fe}_{3} \mathrm{O}_{4}$ onto biochar for heterogeneous activation of PS should possess following advantages. Firstly, biochar is cheaper than most of the heterogeneous catalyst support such as another carbon-base material activated carbon (AC). ${ }^{21}$ Secondly, $\mathrm{Fe}_{3} \mathrm{O}_{4}$ will be distributed on the surface of biochar thus aggregating will be avoided. Thirdly, the powdered biochar can be easily separated from aqueous phase by external magnet. Last but not least, high adsorption capacity of the support was reported to concentrate pollutants onto the surface ${ }^{22}$ or into the interior cavity ${ }^{23}$ of the synthetic catalysts, and then promote radical oxidation processes because of high instantaneous concentration of reactants. Biochar will show high capacity on pollutant enrichment and then improve efficiency of radical oxidation process.

Herein, we conducted municipal sewage sludge as the feedstock for biochar. On one hand, sludge-derived biochar (SDBC) has been proved as an efficient adsorbent for organic pollutants, $^{21,24}$ heavy metals ${ }^{25-27}$ and ammonia nitrogen ${ }^{28}$ due to its porous surface and abundant surface oxygen-containing functional groups. ${ }^{29}$ On the other hand, tremendous yield of sewage sludge has become one of the most serious concerns fronting society today, thus transferring sewage sludge into functional materials is a promising strategy of waste resource utilization to meet with the requirement from both ecology and economy. ${ }^{30}$ Based on above consideration, magnetic sludge-derived biochar (MSDBC) catalyst was prepared by one-step co-precipitation method, and was further employed as adsorbent and persulfate activator to remove organic pollutants. Acid orange 7 (AO7) was chosen as the representative azo dye, which showed certain resistance to biodegradation in conventional aerobic treatment processes. $^{31}$ Characterizations of MSDBC as well as mechanism study revealed the pathway of oxidative degradation process. Influences of $\mathrm{pH}$ and common anions in real wastewater ${ }^{32}$ were also conducted, in which the removal of $\mathrm{AO} 7$ remained consistent. Together with limited iron leaching and remarkable performance in reuse experiments, MSDBC was proved to be a promising catalyst of PS activation for auspicious applications in industries.

\section{Methods and materials}

\subsection{Materials}

Dewatered sewage sludge was collected from Tangxun Lake Municipal Wastewater Plant in Wuhan, China. To control iron loading rate, dried sludge was employed as precursor to prepare MSDBC. The aforementioned sludge was dried at $60{ }^{\circ} \mathrm{C}$ for 24 hours in an oven. AC was purchased from Tianjin Bashi
Chemical Industry Co., Ltd. China. It was ground and passed through a 200 mesh sieve $(0.074 \mathrm{~mm})$, stored in a glass jar for further experiments and labeled granular activated carbon (GAC). Deionized water $(18.0 \mathrm{~m} \Omega \mathrm{cm})$ was obtained from a Millipore Milli-Q system (USA) and used in all of the experiments. All chemicals used were at least analytical reagent grade and used as received without further purification. AO7, sodium persulfate, ferric chloride, ferrous chloride, concentrated sulfuric acid (>98.0\%), hydrochloric acid, hydrofluoric acid, nitric acid, perchloric acid, sodium hydroxide, sodium carbonate, sodium bicarbonate, sodium sulfate, sodium nitrate, sodium dihydrogen phosphate, sodium chloride, sodium bromide, methanol (MeOH) and tert butyl alcohol (TBA) were purchased from local Sinopharm Chemical Reagent Co. Ltd. For electron paramagnetic resonance (EPR) analysis, 5,5dimethyl-1-pyrolene N-oxide (DMPO) (98\%, Adamas Reagent Co. Ltd.) was used.

\subsection{Preparation and characterization of MSDBC}

To prepare MSDBC, $200 \mathrm{~g}$ dried sludge was added into the aqueous solution $(2400 \mathrm{~mL})$ of $\mathrm{FeCl}_{2}(166.7 \mathrm{mM})$ and $\mathrm{FeCl}_{3}$ (333.3 mM), shaken for $30 \mathrm{~min}$. Then, $\mathrm{NaOH}$ solution ( $5 \mathrm{M}$ ) was added dropwise into the mixture under vigorous mechanical shaking, until the $\mathrm{pH}$ of the suspension increased to 10.0. The shaking was then maintained for $30 \mathrm{~min}$. The solid phase was separated by centrifugation at $3000 \mathrm{rpm}$, vacuum dried at $60{ }^{\circ} \mathrm{C}$, and pyrolyzed at $400{ }^{\circ} \mathrm{C}$ for 2 hours in a tubal furnace, with a temperature increasing rate of $10^{\circ} \mathrm{C} \mathrm{min}^{-1}$ and $1 \mathrm{~L} \mathrm{~min}^{-1} \mathrm{~N}_{2}$ sweeping as inert shielding gas. The resulting biochar (labeled MSDBC, vide infra in Section 3.1) was ground and passed through a 200 mesh sieve $(0.074 \mathrm{~mm})$ without further activation. SDBC was prepared by pyrolyzing with aforementioned conditions without co-precipitation of iron salts.

The ash content (weight ratio, wt \%) was measured by combustion of SDBC/MSDBC at $760{ }^{\circ} \mathrm{C}$ for 6 hours in a muffle furnace and calculated by the residue weight ratio of the material. ${ }^{33}$ The elemental composition (C, H, N and S, wt\%) of SDBC and MSDBC were detected by an elemental analyzer (Vario MICRO cube Elementar, German). The content of Fe in the bulk was measured by atomic absorption spectroscopy (AAS) analysis with AAnalyst300 Perkin Elmer, USA after a series of digestion procedures as follows. Firstly, $0.5 \mathrm{~g}$ MSDBC was added into $10 \mathrm{~mL} \mathrm{HNO}_{3}$ solution $(8 \mathrm{M}$ ) in a Politef beaker, heated at $50{ }^{\circ} \mathrm{C}$ for $30 \mathrm{~min}$. Secondly, $5 \mathrm{~mL} \mathrm{HF}$ solution $(23 \mathrm{M})$ was added and the suspension was boiled for $10 \mathrm{~min}$. Then, $7 \mathrm{~mL} \mathrm{HClO}_{4}$ $(12.4 \mathrm{M})$ was added and the suspension was boiled until it became nearly dried. Lastly, $25 \mathrm{~mL} \mathrm{HNO}_{3}$ solution $(0.2 \mathrm{M})$ was added and the suspension was boiled until the residue completely dissolved, followed by diluting with deionized water to $50 \mathrm{~mL}$. The resultant clear liquid was used for AAS measurement and the iron content was calculated according to the dilution ratio.

The porosity of MSDBC was characterized by $\mathrm{N}_{2}$ adsorptiondesorption curves collected by a JW-BK low temperature $\mathrm{N}_{2}$ adsorption instrument from JWGB Sci. \& Tech, China at $-196.15{ }^{\circ} \mathrm{C}$. The specific surface area $\left(S_{\mathrm{BET}}\right)$ was calculated by 
Brunauer-Emmett-Teller (BET) equation. Prior to the $\mathrm{N}_{2}$ adsorption-desorption measurement, MSDBC was firstly dried and degassed at $120{ }^{\circ} \mathrm{C}$ under vacuum for 24 hours. Fourier transform infrared (FTIR) spectroscopy analysis was conducted using the $\mathrm{KBr}$ pellet technique, and over a wavelength range from 400 to $4000 \mathrm{~cm}^{-1}$ under a $4 \mathrm{~cm}^{-1}$ resolution (Vertex 70 Bruker, German). X-ray photoelectron spectroscopy (XPS) analysis equipped with $\mathrm{Al} / \mathrm{Mg} \mathrm{K} \alpha \mathrm{X}$-ray source with $30 \mathrm{eV}$ pass energy in $0.5 \mathrm{eV}$ step over an area of $650 \mu \mathrm{m} \times 650 \mu \mathrm{m}$ to the samples was carried out for $\mathrm{O} 1 \mathrm{~s}$ (SDBC and MSDBC) and Fe 2p (fresh and used MSDBC) regions (AXIS-ULTRA DLD-600W Shimadzu/ Kratos, Japan) at vacuum of $10^{-9}$ Torr, and the results were corrected by a reference of the $\mathrm{C} 1 \mathrm{~s}$ peak from adventitious carbon at $284.8 \mathrm{eV}$ and fitted with Shirley method of background subtraction on XPSpeak4.1 Software. ${ }^{34}$ Scanning electron microscope (SEM) was conducted (Sirion 200 FEI, Netherlands) combined with an electron dispersive X-ray (EDX) analyzer. X-ray diffraction (XRD) analysis was conducted (X'Pert $\mathrm{PRO}$, Netherlands) with $\mathrm{Cu} \mathrm{K} \alpha$ radiation $(\lambda=0.1542 \mathrm{~nm})$ over a $2 \theta$ collection range of $5-90^{\circ}$ with a scanning rate of $6^{\circ} \mathrm{min}^{-1}$. Magnetic property of the MSDBC was determined by magnetization curve using EM4-HVA ELECTROMAGNETIC magnetometer (Lake Shore, USA). The zeta potentials were measured at different pH (2.03-9.11) by Zetasizer Nano series (Nano-ZS90, Malvern, UK) at $25^{\circ} \mathrm{C}$. Firstly, $150 \mathrm{mg}$ of MSDBC was added into a plastic conical flask containing $65 \mathrm{~mL}$ deionized water. Then, the flask was mechanical shaken for 24 hours. Lastly, the resultant suspension was collected for zeta potentials determination in $0.01 \mathrm{mM} \mathrm{NaCl}$ solution. The $\mathrm{pH}$ was adjusted with $0.01 \mathrm{mM} \mathrm{NaOH}$ and $\mathrm{HCl}$. The point of zero charge $\left(\mathrm{pH}_{\mathrm{PZC}}\right)$ was calculated by the zeta potentials under different pHs (2.03-9.11).

\subsection{AO7 removal experiments}

$20 \mathrm{~mL}$ samples (aqueous solution of $0.06 \mathrm{mM} \mathrm{AO7)} \mathrm{were}$ added to $25 \mathrm{~mL}$ vials together with appropriate amounts of sodium persulfate and MSDBC. The vials were closed and shaken in a mechanical shaker for $100 \mathrm{~min}$. Periodically one sample of $1 \mathrm{~mL}$ was taken out at a time interval of $20 \mathrm{~min}$ and analyzed AO7 concentration immediately. For the recycle tests, used MSDBC was collected by centrifugation, washed with deionized water and dried at $60{ }^{\circ} \mathrm{C}$ for 24 hours in a drying oven. Other reaction conditions remained the same for the subsequent runs. The initial pH was 5.22 without adjusting and all experiments were carried at $25{ }^{\circ} \mathrm{C}$. All experiments were run in triplicate, and average values were reported.

\subsection{Identification of oxidative radicals}

Oxidative radicals responsible for the degradation process were identified by quenching studies using two different scavengers, that is, MeOH and TBA. EPR studies coupled with DMPO as a spin-trapping agent were conducted to further identify the main reactive oxygen species. A solution containing $20 \mathrm{mM}$ DMPO, 1.85 mM PS was prepared at $\mathrm{pH}$ value of 3.01, 5.22 and 9.11, and then MSDBC was added to initiate the reaction. After 5 min of reaction, samples were taken out and analyzed on a spectrometer at room temperature (JEOL FA200, Japan). EPR measurements were conducted using a radiation of $9.147 \mathrm{GHz}$ (X band) with a modulation frequency of $100 \mathrm{kHz}$, modulation width of $0.1 \mathrm{mT}$, sweep width of $20 \mathrm{mT}$, center field of $326.0 \mathrm{mT}$, scan time of $60 \mathrm{~s}$, time constant of $0.03 \mathrm{~s}$, and microwave power of $5 \mathrm{~mW}$. All experiments were carried out at $25^{\circ} \mathrm{C}$.

\subsection{Analytic methods}

Quantitative analysis of AO7 was performed using a visible-light spectrophotometer (HACH DR 2500, USA) at the characteristic wavelength of $486 \mathrm{~nm} .{ }^{11}$ The total iron leaching was detected by AAS analysis with AAnalyst300 Perkin Elmer, USA.

\section{Results and discussion}

\subsection{Characterization}

The elemental content of SDBC and MSDBC was firstly investigated and listed in Table 1. Large amount of ashes, which were defined as the solid residuals after combustion experiments, could be found in both SDBC and MSDBC. Most of these ashes were proposed as metal oxides such as $\mathrm{SiO}_{x}, \mathrm{Al}_{2} \mathrm{O}_{3}$, iron oxide, etc. and inorganic salts of alkali metals or alkaline earth metals. The content of ashes in MSDBC (65.37\%) further increased $20.23 \%$ comparing with that of SDBC $(45.15 \%)$, which was mainly attributed to the introducing of magnetic iron component. Also, this difference was highly consistent with the AAS measurements, in which the content of iron was $21.96 \%$ in weight. On the other hand, nitrogen and sulfur was found rich in both SDBC and MSDBC, which was in agreement with the facts that sewage sludge was consist of organic compounds, macro- and micronutrients, trace elements, micro-organisms and micro pollutants.

Fig. 1a represented the XRD patterns of MSDBC in which the presence of quartz (PDF: 46-1045) and calcite (PDF: 47-1743) could be found. ${ }^{35}$ Meanwhile, $\mathrm{Fe}_{3} \mathrm{O}_{4}$ (PDF: $\left.65-3107\right)^{3}$ was also found as the main crystalline phase on the surface of MSDBC. The room-temperature magnetization hysteresis curve was measured via vibrating sample magnetometer (VSM) to exhibit the appropriateness of ferromagnetic materials. This was attained from plots of magnetization $(M)$ against the magnetic field (Oe) as presented S-like curve in Fig. 1b. The saturation magnetization $\left(M_{\mathrm{s}}\right)$ of the MSDBC was calculated as $8.49 \mathrm{emu}$ $\mathrm{g}^{-1}$, which was ample to be separated from aqueous solution by a permanent magnet. ${ }^{36}$ These results confirmed the magnetic properties of MSDBC. Fig. 1c showed the results of zeta potential measurement. The $\mathrm{pH}_{\mathrm{PZC}}$ was calculated to be 5.3 .

Table 1 Content of ashes (wt\%) and various elements (wt \%) in SDBC and MSDBC

\begin{tabular}{llllll}
\hline Sample & Ashes $^{a}(\%)$ & $\mathrm{C}^{b}(\%)$ & $\mathrm{H}^{b}(\%)$ & $\mathrm{N}^{b}(\%)$ & $\mathrm{S}^{b}(\%)$ \\
\hline SDBC & 45.14 & 57.19 & 5.01 & 3.47 & 2.56 \\
MSDBC & 65.37 & 51.34 & 4.37 & 2.79 & 2.13
\end{tabular}

${ }^{a}$ Based on the weight of combusted SDBC/MSDBC. ${ }^{b}$ Based on the remaining weight excluding ashes. 

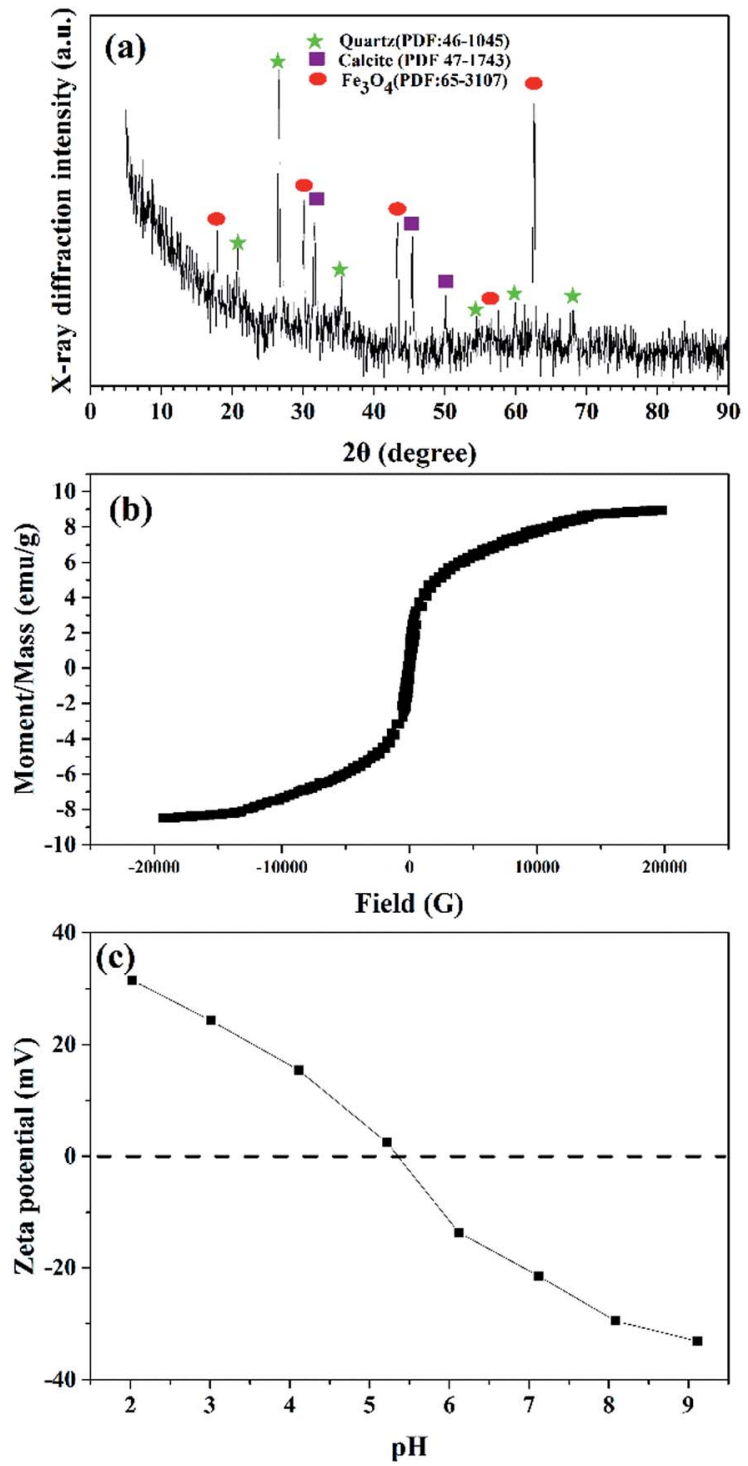

Fig. 1 (a) XRD patterns of MSDBC, (b) magnetization curves measured at room temperature for MSDBC and (c) zeta potentials result of MSDBC.

SEM image was shown in Fig. 2a. The results suggested that uniform $\mathrm{Fe}_{3} \mathrm{O}_{4}$ particles were distributed on the surface of the MSDBC with porous structure. SEM-EDX results (Fig. 2b) further confirmed the existence of Fe species, and the atom and weight ratio of iron on the surface of MSDBC was detected as $11.56 \%$ and $23.13 \%$ respectively. The AAS measurement result of digested iron (vide supra in Section 2.2) indicated iron weight ratio in MSDBC bulk was $219.63 \mathrm{mg} \mathrm{g}^{-1}$ (weight ratio of $21.96 \%$ ), which was similar to the data of EDX measurement. The abovementioned result suggested iron components distributed nearly uniformly, not only on the surface but also in the interior of MSDBC. The uniform distribution of iron contents should be attributed to the one-step synthetic method by pyrolyzing sludge after co-precipitation.

The isotherm of MSDBC was depicted as Fig. 3a, which was of type IV shape and displayed the H2-type hysteresis loop. ${ }^{37}$ The

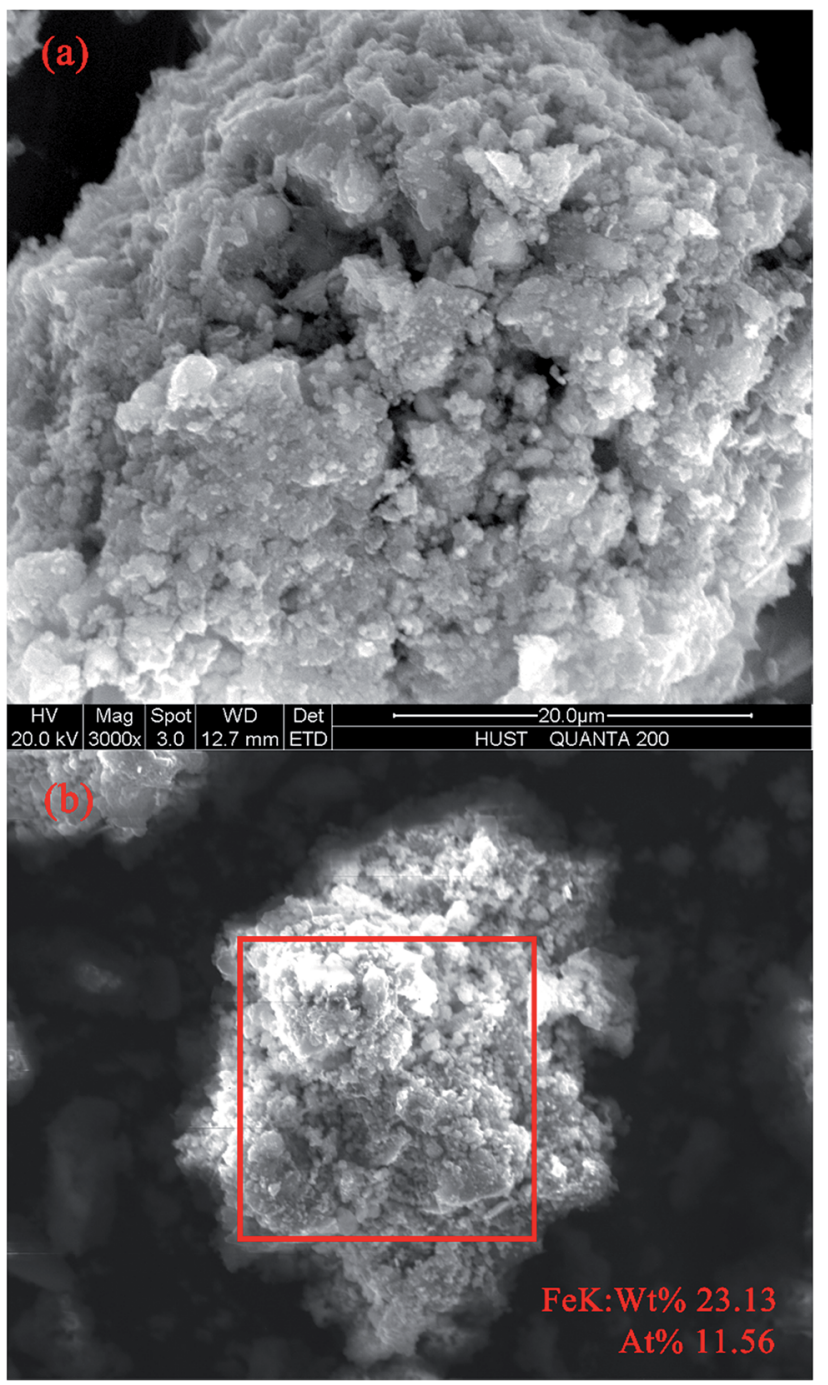

Fig. 2 (a) SEM image and (b) SEM-EDX results of MSDBC.

pore size distribution curve was shown in the insert figure. Barrett-Joyner-Halenda (BJH) methods indicated the average pore size to be $8.217 \mathrm{~nm}$, and $S_{\mathrm{BET}}$ was calculated as $65.47 \mathrm{~m}^{2}$ $\mathrm{g}^{-1}$. The abovementioned results suggested a mesoporous surface $^{38}$ of MSDBC with high $S_{\mathrm{BET}}$, which hinted the high adsorption capacity of MSDBC on AO7. FTIR spectra of SDBC and MSDBC were shown in Fig. 3b. Peaks at about $3427 \mathrm{~cm}^{-1}$ (-OH stretching), $1627 \mathrm{~cm}^{-1}(\mathrm{C}=\mathrm{O}),{ }^{28} 1050 \mathrm{~cm}^{-1}(\mathrm{C}-\mathrm{OH}$ vibration of carboxylic), ${ }^{24} 800 \mathrm{~cm}^{-1}$ (aromatic $\left.\mathrm{C}-\mathrm{H}\right)^{24}$ and 540 $\mathrm{cm}^{-1}(-\mathrm{C}-\mathrm{Br}-)^{39}$ were detected on both of fresh and used MSDBC and SDBC. Peak at $470 \mathrm{~cm}^{-1}$ was only detected on the spectra of fresh and used MSDBC, which should be assigned to $\mathrm{Fe}-\mathrm{O}$ stretch of $\mathrm{Fe}_{3} \mathrm{O}_{4} \cdot{ }^{39}$ The peak at $1264 \mathrm{~cm}^{-1}$ only appeared on the spectra of SDBC, was assigned to symmetric vibration of carboxylate -COO-. ${ }^{40}$ The broad band in the region from 1510 to $1670 \mathrm{~cm}^{-1}$ can both be assigned to $\mathrm{C}=\mathrm{O}$ vibration, while this peak centered at $1645.3 \mathrm{~cm}^{-1}$ in SDBC and at $1626.3 \mathrm{~cm}^{-1}$ in fresh MSDBC. Also the intensity of this peak was stronger for fresh MSDBC under identical conditions. The abovementioned differences between the spectra of SDBC and MSDBC may raise 

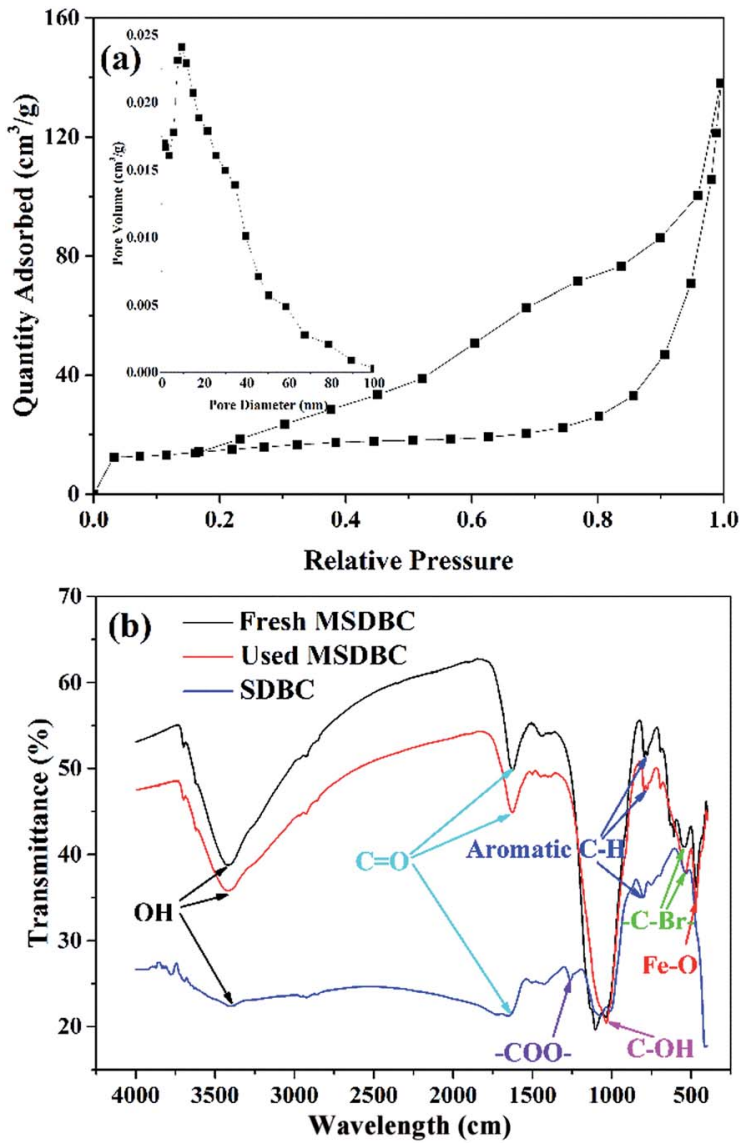

Fig. 3 (a) Nitrogen adsorption-desorption isotherm of MSDBC, insert figure: the corresponding $\mathrm{BJH}$ adsorption pore size distribution curve and (b) FTIR spectra of fresh and used MSDBC and SDBC.

from the chemical bond of $\mathrm{Fe}-\mathrm{O}-\mathrm{C}$ between the Fe species and carbon components on the surface of MSDBC, ${ }^{40}$ and the introducing of $\mathrm{Fe}^{3+}$ favored oxygen-containing functional groups generation, leading to the fact that most peaks in MSDBC was stronger than these of SDBC. Similar phenomena has also been reported in literatures. ${ }^{29,41,42}$ When $\mathrm{Fe}^{3+}$ was introduced, it would conjunct with biomass in small area and be carbonized as small nanosheet. The $\mathrm{Fe}^{3+}$ could be seen as the "separation agent" which would "cut" the biochar to many minces. Functional groups in sludge such as $-\mathrm{OH},-\mathrm{COOH},-\mathrm{NH}_{2}$ and $-\mathrm{C}=\mathrm{O}$ could be conjoined through condensation reactions. ${ }^{29}$

To confirm or disprove the existence of metal-O-C bonds, XPS spectra of O 1s in SDBC and MSDBC were shown in Fig. 4a. In the case of SDBC, two peaks centered at 533.2 and $531.2 \mathrm{eV}$ should be attributed to the $\mathrm{O} 1 \mathrm{~s}$ spectra in $\mathrm{C}-\mathrm{O}$ and $\mathrm{C}=\mathrm{O}$ groups, respectively. ${ }^{43}$ The peak of $\mathrm{C}=\mathrm{O}$ was weaker than that of $\mathrm{C}-\mathrm{O}$ from the view of intensity, indicating the existence of more abundant $\mathrm{C}-\mathrm{O}$ groups on the surface of $\mathrm{SDBC}$ than $\mathrm{C}=\mathrm{O}$ groups, which was also proved by previous spectra of FTIR. Alternatively, O 1s spectra of MSDBC contained four peaks. Besides the two similar peaks as discussed above, another two distinguished peaks that centered at 531.8 and $529.8 \mathrm{eV}$ should be found and attributed to $\mathrm{Fe}-\mathrm{O}-\mathrm{C}$ and $\mathrm{Fe}-\mathrm{O}$ bonds, respectively. ${ }^{44}$ This result further confirmed the existence of $\mathrm{Fe}-\mathrm{O}-\mathrm{C}$
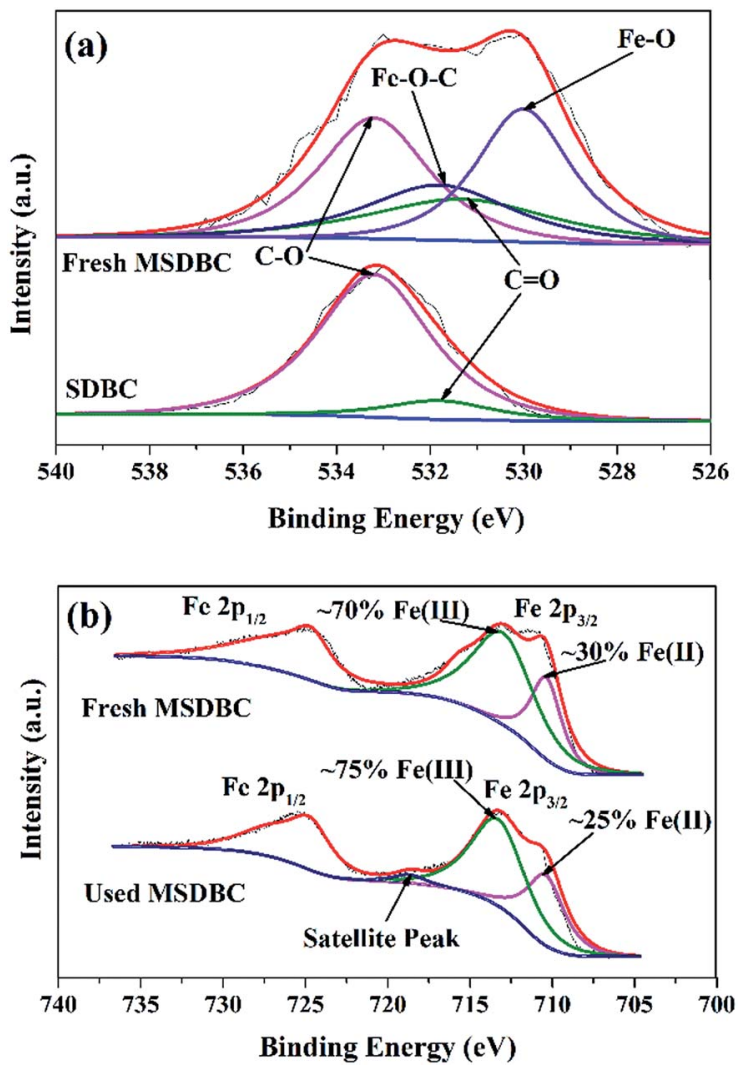

Fig. 4 (a) XPS spectra of the $O$ 1s spectral region on SDBC and fresh $M S D B C$ (the pink lines represent $C-O$, the green lines represent $C=O$, the blue line represents $\mathrm{Fe}-\mathrm{O}-\mathrm{C}$ and the purple line represents $\mathrm{Fe}-\mathrm{O}$ ) and (b) XPS spectra of the Fe $2 \mathrm{p}$ spectral region on both of fresh and used MSDBC (the pink lines represent Fe $2 p_{3 / 2}$ peak of Fe( $(1)$, the green lines represent that of $\mathrm{Fe}($ III) and the blue line represents satellite peak).

bond on the surface of MSDBC, indicating strong interfacial interactions between $\mathrm{Fe}_{3} \mathrm{O}_{4}$ and carbon components that benefitted the stability of MSDBC.

XPS spectra of the Fe 2p spectral region for fresh and used MSDBC further confirmed the existence of $\mathrm{Fe}_{3} \mathrm{O}_{4}$ (Fig. 4b). For instance, signals from $\mathrm{Fe} 2 \mathrm{p}_{1 / 2}$ at around $725 \mathrm{eV}$ could be observed in XPS spectra in both fresh and used MSDBC. Two peaks from $\mathrm{Fe} 2 \mathrm{p}_{3 / 2}$ that centered at $710 \mathrm{eV}$ and $713 \mathrm{eV}$ are indicative of $\mathrm{Fe}(\mathrm{II})$ and $\mathrm{Fe}(\mathrm{III})$, respectively. ${ }^{45}$ The relative peak areas of the two peaks from $\mathrm{Fe} 2 \mathrm{p}_{3 / 2}$ indicated $30 \%$ and $25 \%$ of $\mathrm{Fe}(\mathrm{II})$ on the surface of fresh and used MSDBC respectively, indicated some of $\mathrm{Fe}(\mathrm{II})$ was oxidated into $\mathrm{Fe}(\mathrm{III})$ by persulfate during the reaction (vide infra in Section 3.2). ${ }^{3}$ The $\mathrm{Fe}(\mathrm{II}) / \mathrm{Fe}(\mathrm{III})$ ratio on the surface of fresh MSDBC was $3 / 7$, less than not only the theoretical one of $1 / 2$ but also the detected value of $0.35 / 0.65$ in standard $\mathrm{Fe}_{3} \mathrm{O}_{4}$ sample. ${ }^{46}$ This phenomenon should be attributed to that SDBC itself always contains some iron impurities rather than $\mathrm{Fe}_{3} \mathrm{O}_{4}{ }^{33} \mathrm{Fe} 2 \mathrm{p}_{3 / 2}$ spectra for $\mathrm{Fe}_{3} \mathrm{O}_{4}$ has been previously reported without any satellite peak. ${ }^{46}$ The satellite peak of $\mathrm{Fe} 2 \mathrm{p}_{3 / 2}$ for fresh MSDBC was nearly negligible. However, after it was used for catalytic degradation (vide infra in Section 3.2), a satellite peak of Fe $2 \mathrm{p}_{3 / 2}$ centered at $718 \mathrm{eV}$ was observed in used MSDBC. The transforming of Fe(II) to Fe(III) 
was responsible to this phenomenon. However, the $\mathrm{Fe}(\mathrm{II}) / \mathrm{Fe}(\mathrm{III})$ ratio was maintained as $0.25 / 0.75$ and the satellite peak was very weak, indicated the high stability of MSDBC.

Above results indicated the successful preparation of MSDBC through feasible method, and MSDBC appeared a porous surface with abundant $\mathrm{Fe}_{3} \mathrm{O}_{4}$ and oxygen-containing functional groups. Both of these two components have been reported to activate PS successfully, ${ }^{\mathbf{2 , 4 5 , 4 7}}$ implicating MSDBC as a good candidate for PS activation.

\subsection{Removal of $\mathrm{AO7}$}

Initial assays were carried out to test AO7 removal by (1) $1.85 \mathrm{mM}$ PS alone, (2) $1 \mathrm{~g} \mathrm{~L}^{-1}$ MSDBC alone, (3) $1 \mathrm{~g} \mathrm{~L}^{-1}$ GAC
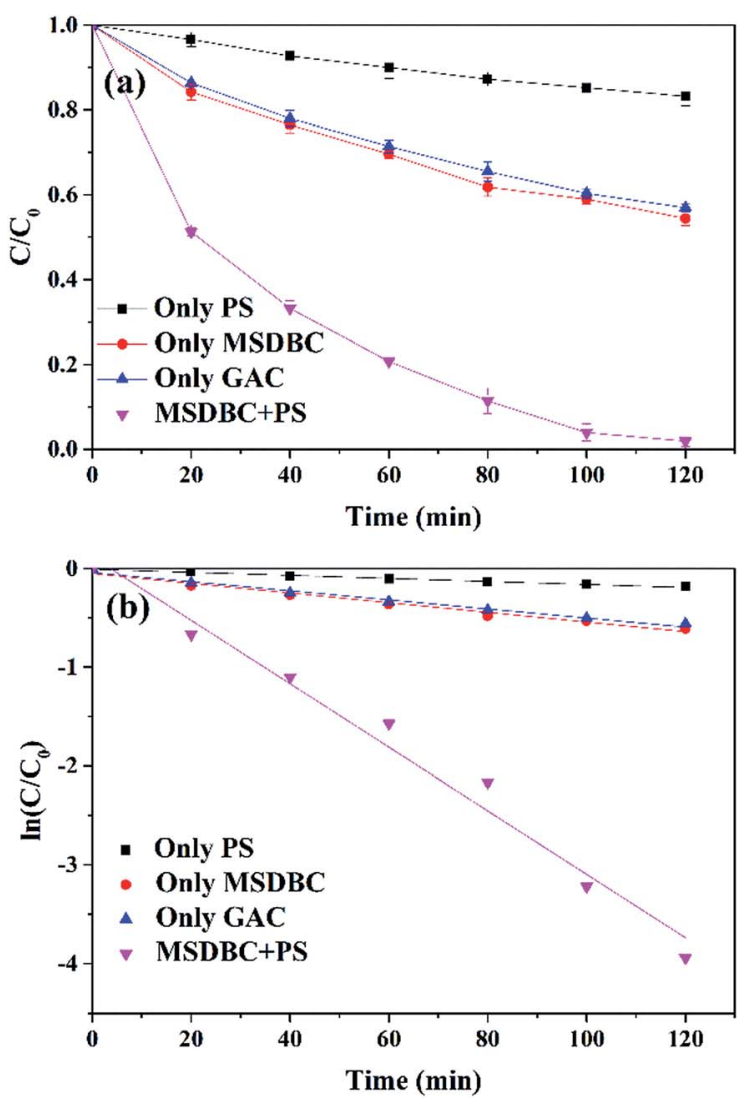

Fig. 5 Degradation and/or adsorption of $A O 7$ by (1) PS (1.85 mM) alone, (2) MSDBC (1 g L-1) alone, (3) GAC $\left(1 \mathrm{~g} \mathrm{~L}^{-1}\right)$ alone (4) MSDBC (1 g $\left.\mathrm{L}^{-1}\right) / \mathrm{PS}(1.85 \mathrm{mM})$. Other reaction conditions: $[\mathrm{AO}]_{0}=0.06 \mathrm{mM}$ and $\mathrm{pH}=5.22$. (a) $\mathrm{AO} 7$ removal and (b) pseudo-first-order kinetic curves for $\mathrm{AO} 7$ removal. alone and (4) MSDBC/PS system $\left(1 \mathrm{~g} \mathrm{~L}^{-1}\right.$ and $1.85 \mathrm{mM}$ respectively). Results showed (Fig. 5a) that PS alone was sluggish on AO7 removal (16.8\%), consistent with the fact that PS oxidation required activator. ${ }^{3}$ Meanwhile, MSDBC itself showed certain removal efficiency $(45.5 \%)$, which was due to the adsorption that raised from the porous structure and abundant oxygencontaining functional groups of MSDBC. It is worth to emphasize that, this adsorption capacity is even higher than that of GAC, which is widely used as commercial adsorbent, and costly more expensive than MSDBC. ${ }^{21}$ Under the same conditions, GAC alone only exhibited $43.0 \%$ removal. Drastic increase on AO7 removal (98.1\%) was achieved when PS was introduced into the MSDBC adsorption group, suggested PS was successfully activated by MSDBC.

To further confirm the successful activation of PS. The data of aforementioned four groups were fitted using pseudo-firstorder kinetics and pseudo-second-order kinetics models respectively, and the fitting results were listed in Table 2 . The high correlation coefficients $\left(R_{1}{ }^{2},>0.97\right.$ in all groups) suggested that $\mathrm{AO} 7$ removal in all groups could be well expressed by pseudo-first-order kinetics model (Table 2 and Fig. 5b). However, the fitting result of group "MSDBC/PS" by pseudosecond-order kinetics model was not satisfactory as the correlation coefficient $\left(R_{2}^{2}\right)$ was only 0.7117 . In most PS based systems, pseudo-first-order kinetics model was reported to fit data well based on only one target contaminant concentration. ${ }^{\mathbf{1 0}}$ Thus, data were fitted by pseudo-first-order kinetics model to test AO7 removal efficiency in our case and all correlation coefficients $\left(R^{2}\right)$ were shown in the figures.

Rate constant ( $k$ ) of "MSDBC/PS" group (0.0321 $\mathrm{min}^{-1}$ ) was 21.4 and 6.6 times of that of "only PS" $\left(0.0015 \mathrm{~min}^{-1}\right)$ and "only MSDBC" (0.0049 $\mathrm{min}^{-1}$ ) groups respectively, which further confirmed the successfully activation of PS by MSDBC. Additionally, the adsorption ability of MSDBC also contributed to this remarkable performance of oxidative degradation because concentrate pollutants onto the surface may promote radical oxidation processes in the presence of high instantaneous concentration of reactants. Similarly, Fe(II)-GAC/PS was reported to remove COD more efficiently from landfill leachate than $\mathrm{Fe}^{2+} / \mathrm{PS}$ and GAC/PS systems, and the higher efficiency was considered to be attributed to the combination of adsorption by GAC and catalysis of $\mathrm{Fe}(\mathrm{II}){ }^{48} \quad \mathrm{RuO}_{2}-\mathrm{AC} /$ peroxymonosulfate (PMS) system was reported to exhibit higher efficiency on phenol removal than $\mathrm{RuO}_{2}$-zeolite/PMS system because of that higher adsorption capacity of AC promoted surface reaction between phenol and oxidative radicals. ${ }^{22}$

Table 2 Fitting results of AO7 removal data by pseudo-first-order kinetics model and pseudo-second-order kinetics model respectively

\begin{tabular}{lllll}
\hline Group & $\begin{array}{l}\text { Rate constant }\left(k_{1}\right) \text { of pseudo- } \\
\text { first-order kinetics model } \\
\left(\mathrm{min}^{-1}\right)\end{array}$ & $\begin{array}{l}\text { Correlation coefficients }\left(R_{1}{ }^{2}\right) \\
\text { of pseudo-first-order kinetics } \\
\text { model }\end{array}$ & $\begin{array}{l}\text { Rate constant }\left(k_{2}\right) \text { of pseudo- } \\
\text { second-order kinetics model } \\
\left(\mathrm{mM}^{-1} \text { min }^{-1}\right)\end{array}$ & $\begin{array}{l}\text { Correlation coefficients }\left(R_{2}{ }^{2}\right) \\
\text { of pseudo-second-order } \\
\text { kinetics model }\end{array}$ \\
\hline PS alone & 0.0015 & 0.9910 & 0.0283 & 0.9750 \\
MSDBC alone & 0.0049 & 0.9769 & 0.1133 & 0.9735 \\
GAC alone & 0.0046 & 0.9837 & 0.1050 & 0.9774 \\
MSDBC/PS & 0.0321 & 0.9801 & 6.0533 & 0.7117
\end{tabular}


The rate constants of $\mathrm{AO} 7$ removal by different dosages of $\operatorname{MSDBC}\left(0.5,1.0\right.$ and $\left.1.5 \mathrm{~g} \mathrm{~L}^{-1}\right)$ and PS $(1.85,3.70$ and $5.55 \mathrm{mM})$ were shown in Fig. 6. Kinetics rate constant increased sharply with the increase of PS dosage from $1.85 \mathrm{mM}$ to $3.70 \mathrm{mM}$, and the increase was not that obvious when PS dosage further raised to $5.55 \mathrm{mM}$ as rate constant increased from $0.0148,0.0321$ and $0.0491 \mathrm{~min}^{-1}$ with $0.5,1.0$ and $1.5 \mathrm{~g} \mathrm{~L}^{-1}$ of MSDBC, to 0.0169, 0.0337 and $0.0511 \mathrm{~min}^{-1}$, respectively. This phenomenon should be attributed to scavenge of $\mathrm{SO}_{4}{ }^{-}$by superfluous PS introduced into the system when PS concentration is too high. ${ }^{2}$ However, in the three groups of different fixed PS dosages, increase of MSDBC dosages induced drastic increase of AO7 removal efficiency in the whole range of MSDBC dosage from $0.5 \mathrm{~g} \mathrm{~L}^{-1}$ to $1.5 \mathrm{~g} \mathrm{~L}^{-1}$. On one hand, larger MSDBC dosage induced larger adsorption capacity and increased number of reaction sites for persulfate activation. On the other hand, larger adsorption capacity favored surface radicals reaction mentioned above. In conclusion, effects of MSDBC dosage were more obvious than that of PS concentration.

\subsection{Identification of oxidative radicals}

Radical scavenger experiments and EPR studies were carried out to identify oxidative radicals in MSDBC/PS system. Sulfate radicals and hydroxyl radicals were reported as the main oxidative radicals in most system employed PS as oxidant., ${ }^{3,445}$ Two radical scavengers ( $\mathrm{MeOH}$ and TBA) were employed in the scavenger experiments under $\mathrm{pH}$ 5.22. TBA is well known as efficient $\mathrm{OH}^{*}$ scavenger but not sensitive with $\mathrm{SO}_{4}{ }^{-}$because of high reaction rate constants with $\mathrm{OH}^{\cdot}\left(3.8-7.6 \times 10^{8} \mathrm{M}^{-1} \mathrm{~s}^{-1}\right)$ and lower ones with $\mathrm{SO}_{4}{ }^{--}\left(4.0-9.1 \times 10^{5} \mathrm{M}^{-1} \mathrm{~s}^{-1}\right) .{ }^{4}$ Fig. 7a showed quenching results of TBA. Kinetics rate constant of AO7 removal decreased from 0.0321 to $0.0179 \mathrm{~min}^{-1}$ when $18.5 \mathrm{mM}$ TBA was introduced. Further decrease of rate constant from

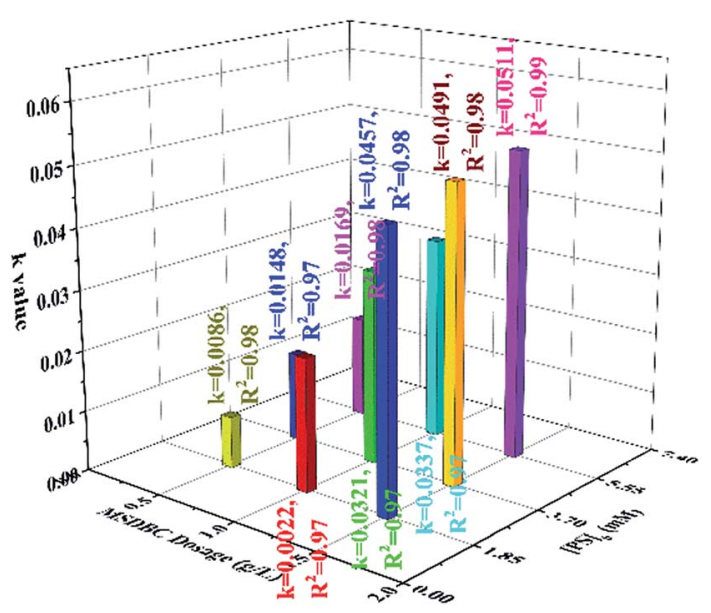

Fig. 6 The rate constants $(k)$ of pseudo-first-order kinetic models for AO7 removal by different MSDBC and PS dosage (the rate constants ( $k$ ) and the correlation coefficients $\left(R^{2}\right)$ were shown above the pillar in the groups of MSDBC dosage $=0.5$ and $1.5 \mathrm{~g} \mathrm{~L}^{-1}$ and below the pillar in the group of $1.0 \mathrm{~g} \mathrm{~L}^{-1}$ ). Reaction conditions: $[\mathrm{PS}]_{0}=1.85,3.70$ and $5.55 \mathrm{mM}, \mathrm{MSDBC}$ dosage $=0.5,1.0$ and $1.5 \mathrm{~g} \mathrm{~L}^{-1},[\mathrm{AO}]_{0}=0.06 \mathrm{mM}$ and $\mathrm{pH}=5.22$.
0.0179 to $0.012 \mathrm{~min}^{-1}$ was observed when TBA concentration increased from $18.5 \mathrm{mM}$ to $370.0 \mathrm{mM}$, suggesting that $\mathrm{OH}^{*}$ contributed to $\mathrm{AO} 7$ removal. Owing to the high reaction rate constants with both of $\mathrm{SO}_{4}{ }^{--}\left(1.2-2.8 \times 10^{9} \mathrm{M}^{-1} \mathrm{~s}^{-1}\right)$ and $\mathrm{OH}^{*}$ (1.6-7.7 $\left.\times 10^{7} \mathrm{M}^{-1} \mathrm{~s}^{-1}\right),{ }^{4} \mathrm{MeOH}$ was employed to quench both of $\mathrm{SO}_{4}{ }^{-}$and $\mathrm{OH}^{*}$ (Fig. 7b). Rate constant of $\mathrm{AO} 7$ removal decreased from 0.0321 to $0.0172 \mathrm{~min}^{-1}$ when $18.5 \mathrm{mM} \mathrm{MeOH}$ was introduced into the reaction. Further decrease of rate constant from 0.0172 to $0.008 \mathrm{~min}^{-1}$ was found when $\mathrm{MeOH}$ concentration increased from $18.5 \mathrm{mM}$ to $370.0 \mathrm{mM}$. With the
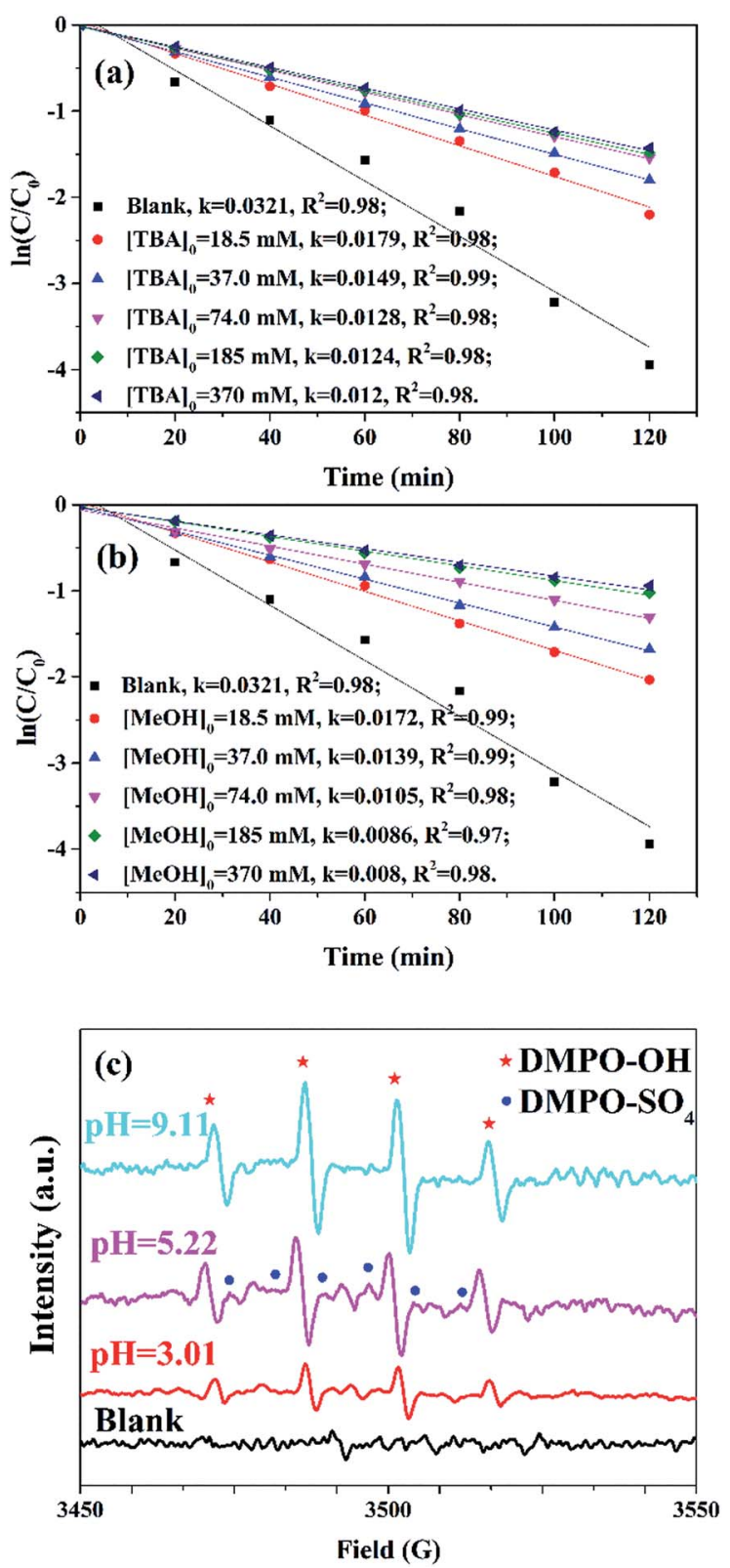

Fig. 7 Pseudo-first-order kinetic curves for AO7 removal by MSDBC/ PS system with different scavengers: (a) TBA and (b) MeOH. Reaction conditions: $\mathrm{MSDBC}$ dosage $=1.0 \mathrm{~g} \mathrm{~L}^{-1},[\mathrm{PS}]_{0}=1.85 \mathrm{mM},[\mathrm{AO}]_{0}=$ $0.06 \mathrm{mM}$ and $[\mathrm{pH}]_{0}=5.22$. (c) EPR spectra of MSDBC/PS system under three different $\mathrm{pH}$ values ( $\star$ represents $\mathrm{OH}^{*}$ adducts and $\bullet$ represents $\mathrm{SO}_{4} \cdot{ }^{\cdot-}$ adducts). 
same amounts of scavengers, rate constants of $\mathrm{MeOH}$ groups were always lower than the case of TBA, suggesting $\mathrm{SO}_{4}{ }^{--}$was also oxidative radicals in MSDBC/PS system. EPR tests with DMPO as spin-trapping agent further confirmed the existence of $\mathrm{SO}_{4}{ }^{--}$and $\mathrm{OH}^{\cdot}$ (Fig. 7c). Both of DMPO-SO ${ }_{4}$ and DMPO-OH signals were observed under three different $\mathrm{pH}$ values of 3.01, 5.22 and $9.11\left(\right.$ DMPO-SO ${ }_{4}: a_{\mathrm{N}}=12.3 \mathrm{G}, a_{\mathrm{H}}=9.6 \mathrm{G}, a_{\mathrm{H}}=1.48 \mathrm{G}$, $a_{\mathrm{H}}=0.78 \mathrm{G}$; DMPO-OH: $a_{\mathrm{N}}=a_{\mathrm{N}}=14.9 \mathrm{G}, g=2.0067$, quartet adduct peaks with characteristic intensities of $1: 2: 2: 1){ }^{49}$ In addition, stronger DMPO-OH signal was observed under $\mathrm{pH}$ 9.11 than these of $\mathrm{pH} 5.22$ and 3.01, indicating that $\mathrm{OH}^{\circ}$ made more contribution under alkaline condition. This phenomenon is attributed to transforming of $\mathrm{SO}_{4}{ }^{--}$into $\mathrm{OH}^{-}$under alkaline condition. ${ }^{47}$

\subsection{Stability and reuse of MSDBC}

Iron leaching from MSDBC was tested under different pHs (Fig. 8a). Negligible iron leaching was found under $\mathrm{pH}$ values from 5.22 to 9.11 during the oxidative process. This phenomenon demonstrated heterogeneous MSDBC with a good stability for practical applications in real wastewater treatment. Only under extreme acidic condition of $\mathrm{pH} 2.03$ and 3.01, very small amount of iron leaching was detected to be 4.69 and $3.06 \mathrm{ppm}$. In the case of $\mathrm{pH} 2.03,4.69 \mathrm{ppm}$ leaching was still limited because it equaled to $4.69 \times 10^{-3} \mathrm{~g}$ iron leached from $1 \mathrm{~g}$ MSDBC under this strong acidic condition. However, weight
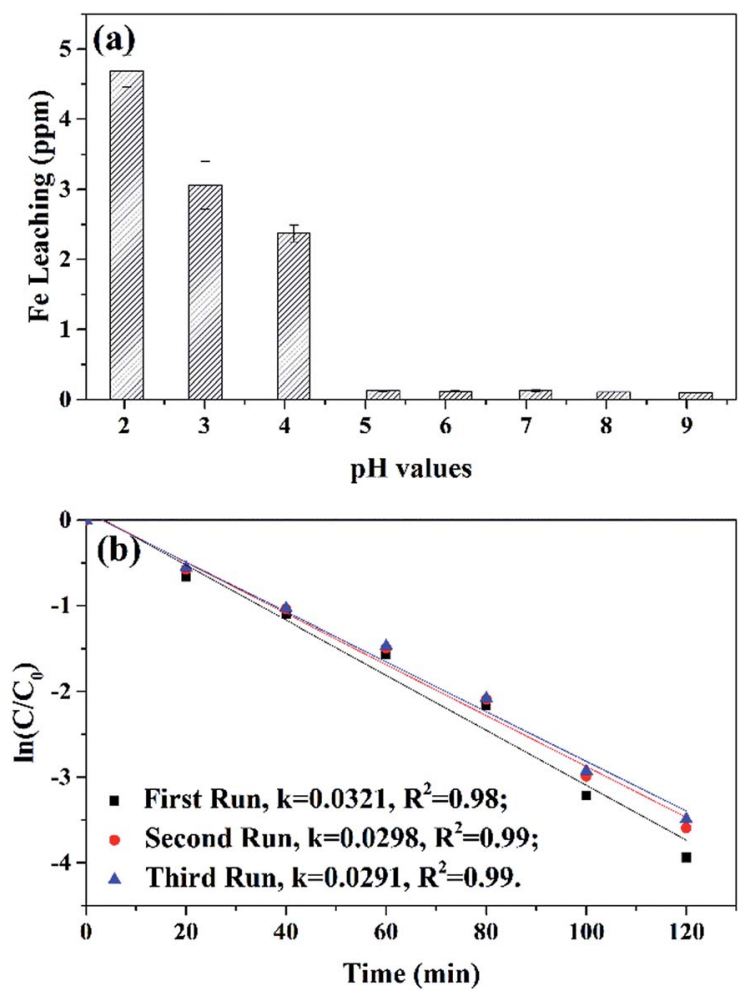

Fig. 8 (a) Iron leaching from MSDBC under different $\mathrm{pH}$ values and (b) pseudo-first-order kinetic curves for $\mathrm{AO} 7$ removal in reuse experiments. Reaction conditions: $\mathrm{MSDBC}$ dosage $=1.0 \mathrm{~g} \mathrm{~L}^{-1},[\mathrm{PS}]_{0}=$ $1.85 \mathrm{mM},[\mathrm{AO} 7]_{0}=0.06 \mathrm{mM}$ and $[\mathrm{pH}]_{0}=5.22$. ratio of iron in MSDBC bulk was detected as $219.63 \mathrm{mg} \mathrm{g}^{-1}$, representing that only $2.14 \%$ weight ratio of iron oxide was dissolved into aqueous solution.

Reuse performance represents one of the most important properties of heterogeneous catalysts. ${ }^{50}$ In our case MSDBC was reused for three times for the oxidative degradation of $\mathrm{AO} 7$ (Fig. 8b), in which the plot of rate constant almost overlapped with each other, suggesting the good reuse performance of MSDBC. This reuse performance originated from its simple preparation method of pyrolysis, was also consistent with the unchanged FTIR and XPS spectra before and after oxidative degradation in Characterization section, and was in highly agreement with its aforementioned negligible leaching during the process.

\subsection{Effects of $\mathrm{pH}$ and common inorganic anions on $\mathrm{AO7}$ removal}

The presence of inorganic anions such as $\mathrm{HCO}_{3}{ }^{-}, \mathrm{CO}_{3}{ }^{2-}$, $\mathrm{H}_{2} \mathrm{PO}_{4}{ }^{-}, \mathrm{SO}_{4}{ }^{2-}, \mathrm{NO}_{3}{ }^{-}, \mathrm{Br}^{-}$and $\mathrm{Cl}^{-}$etc. can react with free radicals through electron exchange and thus influence the efficiency of AOPs. This efficiency was also strongly influence by the $\mathrm{pH}$ of wastewater. Thus it is important to evaluate the oxidative potential of MSDBC/PS system under different $\mathrm{pHs}$ and common anions which exist abundantly in industrial and sewage water.

Influences of initial $\mathrm{pH}$ values (2.03-9.11) on $\mathrm{AO} 7$ removal were shown in Fig. 9. Acidic condition favored $\mathrm{AO} 7$ removal. Rate constant increased from 0.007 to $0.0517 \mathrm{~min}^{-1}$ when $\mathrm{pH}$ decreased from 9.11 to 2.03. These results were in agreement with some previous works. ${ }^{4,47,51}$ This phenomenon may be attributed to two facts. On one hand, as $\mathrm{pH}_{\mathrm{PZC}}$ of MSDBC was measured to be 5.3, MSDBC will be positively charged under acidic conditions. Meanwhile, AO7 molecules have two $\mathrm{p} K_{\mathrm{a}}$ values of 1 for the $-\mathrm{SO}_{3} \mathrm{H}$ group and 11 for the naphthalene, respectively. AO7 will exist as negatively charged monoprotonated form in the aqueous solution for $\mathrm{pH}$ values between 2.03 and 9.11. ${ }^{51}$ Thus, lower $\mathrm{pH}(\mathrm{pH}<5.3)$ will favor AO7 adsorption

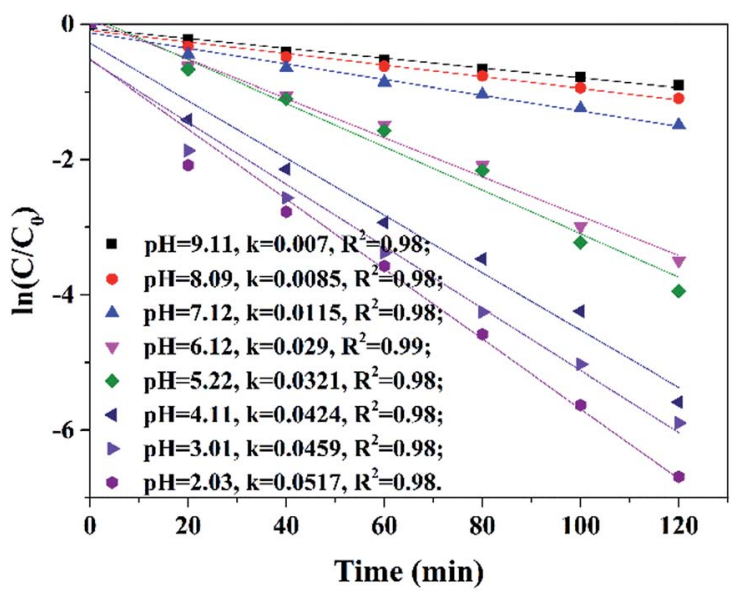

Fig. 9 Pseudo-first-order kinetic curves for $\mathrm{AO} 7$ removal under different initial $\mathrm{pH}$ values. Reaction conditions: $\mathrm{MSDBC}$ dosage $=1.0 \mathrm{~g}$ $\mathrm{L}^{-1},[\mathrm{PS}]_{0}=1.85 \mathrm{mM}$ and $[\mathrm{AO} 7]_{0}=0.06 \mathrm{mM}$. 
by MSDBC because of electrostatic attraction between the anionic dye molecules and MSDBC surface. On the other hand, Leng et al. suggested that rapid decay of $\mathrm{SO}_{4}{ }^{--}$resulting from the reactions with hydroxyl ions also contributed to the decrease of organic pollutants removal efficiency. ${ }^{47}$

Effects of common anions $\left(\mathrm{HCO}_{3}{ }^{-}, \mathrm{CO}_{3}{ }^{2-}, \mathrm{H}_{2} \mathrm{PO}_{4}{ }^{-}, \mathrm{SO}_{4}{ }^{2-}\right.$, $\mathrm{NO}_{3}{ }^{-}, \mathrm{Br}^{-}$and $\mathrm{Cl}^{-}$, initial concentration of $1.85 \mathrm{mM}$ ) were shown in Fig. 10a. $\mathrm{NO}_{3}{ }^{-}$slightly inhibited $\mathrm{AO} 7$ removal as rate constant decreased from 0.0321 to $0.0280 \mathrm{~min}^{-1}$ when $1.85 \mathrm{mM}$ $\mathrm{NO}_{3}{ }^{-}$was introduced into the reaction. This phenomenon was attributed to the fact that nitrate radicals $\left(\mathrm{NO}_{3}{ }^{\circ}, E^{0}=2-2.2 \mathrm{~V}\right)$ was produced by reactions between $\mathrm{NO}_{3}{ }^{-}$and oxidative radicals $\left(\mathrm{SO}_{4}{ }^{-}-\mathrm{OH}{ }^{*}\right)$ of less reactivity by eqn (3) and (4). ${ }^{52} \mathrm{HCO}_{3}{ }^{-}, \mathrm{CO}_{3}{ }^{2-}$ and $\mathrm{HPO}_{4}{ }^{2-}$ also inhibited the reaction by similar pathways, in which less reactive radicals $\left(\mathrm{HCO}_{3}{ }^{\circ}, \mathrm{CO}_{3}{ }^{\circ}, \mathrm{H}_{2} \mathrm{PO}_{4}{ }^{\circ}\right.$ by eqn (5)$(10))^{7,52}$ were generated by the reaction of $\mathrm{SO}_{4}{ }^{-} / \mathrm{OH}^{*}$ with anions. Alternatively, $\mathrm{HCO}_{3}{ }^{-}$has been reported to favor phenol removal by $\mathrm{CuO}-\mathrm{Fe}_{3} \mathrm{O}_{4} / \mathrm{PS}$ system because of its $\mathrm{pH}$ buffering stability (by eqn (11) and (12)) to fix pH constant at $8.0 \pm 0.5 .^{3}$ However, in our case, when $\mathrm{HCO}_{3}{ }^{-}$was introduced in our case, MSDBC was negatively charged due to the weak alkaline $\mathrm{pH}$ and its adsorption capacity on anionic AO7 decreased, therefore inhibited $\mathrm{AO} 7$ removal. $1.85 \mathrm{mM} \mathrm{SO}_{4}{ }^{2-}$ was also found to inhibit AO7 removal. This phenomenon should be attributed to decrease of oxidative reduction potential of $\mathrm{SO}_{4}{ }^{\cdot-} / \mathrm{SO}_{4}{ }^{2-}$ under
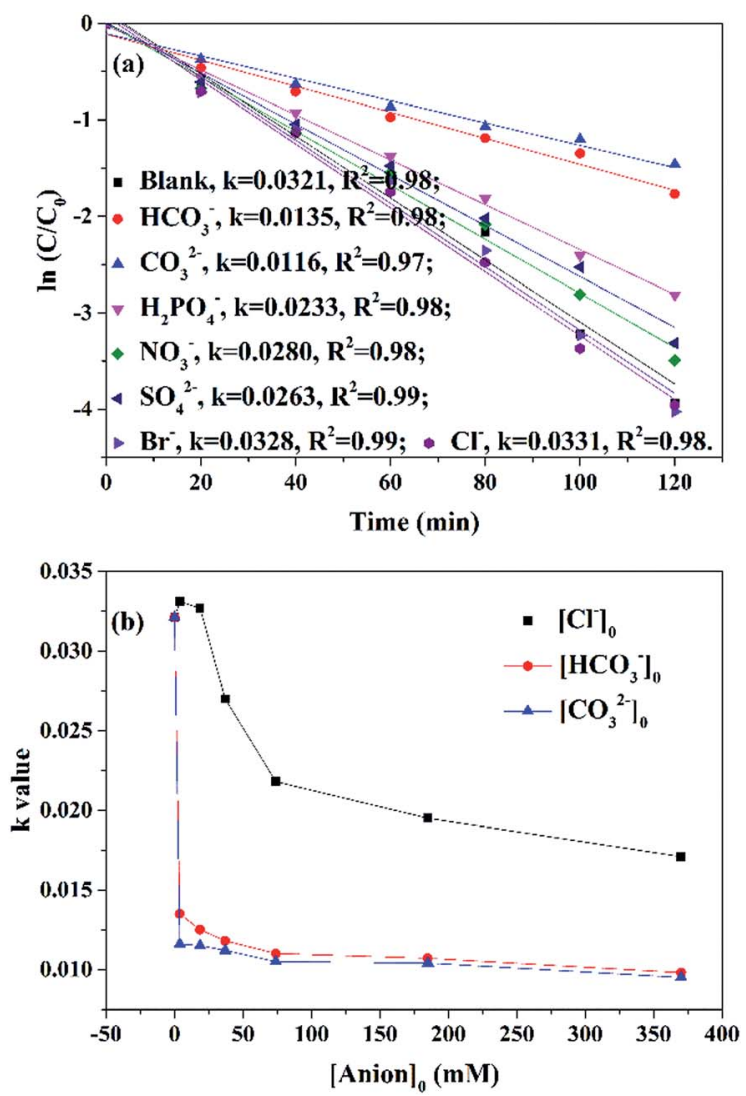

Fig. 10 (a) Effects of common anions on $\mathrm{AO} 7$ removal. Reaction conditions: [anions] $]_{0}=1.85 \mathrm{mM}$. (b) Effects of anions concentration on AO7 removal. Reaction conditions: [anions] $]_{0}=1.85-370 \mathrm{mM}$. high $\mathrm{SO}_{4}{ }^{--}$concentration, leading to less efficient activation of PS. ${ }^{52}$

$$
\begin{aligned}
& \mathrm{NO}_{3}{ }^{-}+\mathrm{SO}_{4}{ }^{\cdot-} \rightarrow \mathrm{NO}_{3}{ }^{\cdot}+\mathrm{SO}_{4}{ }^{2-}, k=5.5 \times 10^{5} \mathrm{M}^{-1} \mathrm{~s}^{-1} \\
& \mathrm{NO}_{3}{ }^{-}+\mathrm{OH}^{\cdot} \rightarrow \mathrm{NO}_{3}{ }^{-}+\mathrm{OH}^{-}, k<5.0 \times 10^{5} \mathrm{M}^{-1} \mathrm{~s}^{-1} \\
& \mathrm{HCO}_{3}{ }^{-}+\mathrm{SO}_{4}{ }^{--} \rightarrow \mathrm{HCO}_{3}{ }^{-}+\mathrm{SO}_{4}{ }^{2-}, \\
& k=9.1 \times 10^{6} \mathrm{M}^{-1} \mathrm{~s}^{-1} \\
& \mathrm{HCO}_{3}{ }^{-}+\mathrm{OH}^{\cdot} \rightarrow \mathrm{HCO}_{3}{ }^{-}+\mathrm{OH}^{-}, \\
& k=8.5 \times 10^{8} \mathrm{M}^{-1} \mathrm{~s}^{-1} \\
& \mathrm{CO}_{3}^{2-}+\mathrm{SO}_{4}^{\cdot-} \rightarrow \mathrm{CO}_{3}^{\cdot-}+\mathrm{SO}_{4}^{2-}, \\
& k=6.1 \times 10^{6} \mathrm{M}^{-1} \mathrm{~s}^{-1} \\
& \mathrm{CO}_{3}^{2-}+\mathrm{OH}^{\cdot} \rightarrow \mathrm{CO}_{3}^{\cdot-}+\mathrm{OH}^{-}, k=3.9 \times 10^{8} \mathrm{M}^{-1} \mathrm{~s}^{-1} \\
& \mathrm{H}_{2} \mathrm{PO}_{4}^{-}+\mathrm{SO}_{4}{ }^{--} \rightarrow \mathrm{H}_{2} \mathrm{PO}_{4}{ }^{-}+\mathrm{SO}_{4}{ }^{2-}, \\
& k<7.0 \times 10^{4} \mathrm{M}^{-1} \mathrm{~s}^{-1} \\
& \mathrm{H}_{2} \mathrm{PO}_{4}^{-}+\mathrm{OH}^{\cdot} \rightarrow \mathrm{H}_{2} \mathrm{PO}_{4}{ }^{-}+\mathrm{OH}^{-}, \\
& k=(1.0-2.0) \times 10^{4} \mathrm{M}^{-1} \mathrm{~s}^{-1} \\
& \mathrm{H}_{2} \mathrm{CO}_{3}(\mathrm{aq}) \rightarrow \mathrm{H}^{+}+\mathrm{HCO}_{3}^{-}, \mathrm{p} K_{\mathrm{a}}=6.37 \\
& \mathrm{HCO}_{3}{ }^{-} \rightarrow \mathrm{H}^{+}+\mathrm{CO}_{3}{ }^{2-}, \mathrm{p} K_{\mathrm{a}}=10.33
\end{aligned}
$$

Distinguished from above anions, $1.85 \mathrm{mM} \mathrm{of} \mathrm{Cl}^{-}$and $\mathrm{Br}^{-}$ enhanced efficiency of oxidative degradation. Rate constants of AO7 degradation increased from 0.0321 to 0.0331 and 0.0328 min ${ }^{-1}$ with the addition of $\mathrm{Cl}^{-}$and $\mathrm{Br}^{-}$respectively. Halide irons may also react with sulfate and hydroxyl radicals through different processes. ${ }^{53}$ For instance, $\mathrm{Cl}^{\bullet}$ (eqn (13)) and $\mathrm{Cl}_{2}{ }^{-{ }^{-}}$(eqn (14)) may be generated through the quench of sulfate radicals by $\mathrm{Cl}^{-} .{ }^{53}$ However, the quenching reaction (eqn (13)) was reported reversible and the rate constants of forward $\left(2.7-3.4 \times 10^{8} \mathrm{M}^{-1}\right.$ $\left.\mathrm{s}^{-1}\right)$ and reverse pathway $\left(2.0-2.5 \times 10^{8} \mathrm{M}^{-1} \mathrm{~s}^{-1}\right)$ are similar. ${ }^{52,53}$ Under low $\mathrm{Cl}^{-}$concentration, certain amount of $\mathrm{SO}_{4}{ }^{-}-$was quenched, which may help to avoid $\mathrm{SO}_{4}{ }^{-}$quenching by superfluous $\mathrm{SO}_{4}{ }^{-}$and accelerate PS decomposition. ${ }^{54}$ Meanwhile, reverse pathway (eqn (13)) which will undergo under low level of $\mathrm{Cl}^{-}$and $\mathrm{SO}_{4}{ }^{--}$, will regenerate $\mathrm{SO}_{4}{ }^{-}$and maintain oxidation efficiency. ${ }^{53}$

$$
\begin{gathered}
\mathrm{Cl}^{-}+\mathrm{SO}_{4}^{\cdot-} \leftrightarrow \mathrm{Cl}^{\cdot}+\mathrm{SO}_{4}{ }^{2-} \\
\mathrm{Cl}^{-}+\mathrm{Cl}^{\cdot} \leftrightarrow \mathrm{Cl}_{2}{ }^{--}
\end{gathered}
$$

As $\mathrm{HCO}_{3}{ }^{-}$and $\mathrm{CO}_{3}{ }^{2-}$ showed highest inhibition levels and $\mathrm{Cl}^{-}$ showed highest promotion level on AO7 removal respectively, different concentrations of these three anions were introduced into MSDBC/PS system to further study the effects of anions on AO7 removal (Fig. 10b). Rate constants decreased from 0.0135 and $0.0116 \mathrm{~min}^{-1}$ to 0.0098 and $0.0095 \mathrm{~min}^{-1}$ when concentration of $\mathrm{HCO}_{3}{ }^{-}$and $\mathrm{CO}_{3}{ }^{2-}$ increased from 1.85 to $370.0 \mathrm{mM}$ respectively. As the rate constant was calculated as $0.0049 \mathrm{~min}^{-1}$ on $\mathrm{AO} 7$ adsorption by MSDBC, the aforementioned results suggested that 
oxidation of $\mathrm{AO} 7$ happened even $370.0 \mathrm{mM}$ of $\mathrm{HCO}_{3}{ }^{-}$and $\mathrm{CO}_{3}{ }^{2-}$ was introduced. This may be attributed incomplete quenching of oxidative radicals and/or oxidation of $\mathrm{AO} 7$ by $\mathrm{HCO}_{3}{ }^{\circ}$ and $\mathrm{CO}_{3}{ }^{--}$. Interestingly, further increase of $\mathrm{Cl}^{-}$induced decrease of rate constant of AO7 removal $\left(0.0171 \mathrm{~min}^{-1}\right.$ when $\mathrm{Cl}^{-}$concentration was $370.0 \mathrm{mM}$ ). This is attributed to that high $\mathrm{Cl}^{-}$level favored forward pathway of reaction between $\mathrm{Cl}^{-}$and $\mathrm{SO}_{4}{ }^{-}$(eqn (13)), and $\mathrm{Cl}^{-}$acted as radical quencher. Above data disclosed that most anions inhibited $\mathrm{AO} 7$ removal, the order of inhibition levels is $\mathrm{CO}_{3}{ }^{2-}>\mathrm{HCO}_{3}{ }^{-}>\mathrm{H}_{2} \mathrm{PO}_{4}{ }^{-}>\mathrm{SO}_{4}{ }^{2-}>\mathrm{NO}_{3}{ }^{-}$. Two halide irons, $\mathrm{Cl}^{-}$ and $\mathrm{Br}^{-}$, at low concentration of $1.85 \mathrm{mM}$, showed slightly promotion effects on $\mathrm{AO} 7$ removal. However, high concentration of halide irons inhibited $\mathrm{AO} 7$ removal.

\section{Conclusion}

In this effort, municipal sewage sludge was chosen as the feedstock of biochar, based on which $\mathrm{Fe}_{3} \mathrm{O}_{4}$ particles were successfully loaded by one-step co-precipitation method. Magnetic sludge-derived biochar was therefore prepared, and this material reveals porous structure with remarkable adsorption capacity and magnetic separation ability. $\mathrm{Fe}_{3} \mathrm{O}_{4}$ component and oxygen-containing functional groups on its surface contributed to the generation of high level of oxidative radicals from PS, while and the enrichment of pollutant on the surface was realized. Thus, excellent performance for the treatment of AO7 was achieved via both adsorption and catalytic degradation. MSDBC also exhibited satisfactory stability, remained highly efficient in reuse experiments because little iron leaching can be detected in a broad $\mathrm{pH}$ window. Different from other heterogeneous catalysts, lower $\mathrm{pH}$ value favored $\mathrm{AO} 7$ removal by MSDBC/PS system because the $\mathrm{pH}_{\mathrm{PZC}}$ of MSDBC was evaluated to be 5.3. Furthermore, two halide irons, $\mathrm{Cl}^{-}$and $\mathrm{Br}^{-}$can promote $\mathrm{AO} 7$ removal under low concentrations. These unique behaviors of MSDBC/PS system may be reflected to have superior potential of full-scale application for wastewater treatment. Furthermore, this approach may also be considered as feasible waste resource utilization that converts the solid waste of sewage sludge into stable, cheap and multifunctional bioresource.

\section{Acknowledgements}

This project was funded by National Science Foundation of China [grant number 21671072], Shenzhen Science and Technology Development Funds (No. JCYJ20160429182628979), and Chutian Scholar Foundation from Hubei province, China. The authors also thank the Analytical and Testing Center of Huazhong University of Science and Technology for help in SEMEDX, FTIR, XRD and XPS analysis.

\section{References}

1 C. G. Niu, Y. Wang, X. G. Zhang, G. M. Zeng, D. W. Huang, M. Ruan and X. W. Li, Bioresour. Technol., 2012, 126, 101106.
2 J. Yan, L. Han, W. Gao, S. Xue and M. Chen, Bioresour. Technol., 2015, 175, 269-274.

3 Y. Lei, C. S. Chen, Y. J. Tu, Y. H. Huang and H. Zhang, Environ. Sci. Technol., 2015, 49, 6838-6845.

4 C. Sun, R. Zhou, E. Jianan, J. Sun and H. Ren, RSC Adv., 2015, 5, 57058-57066.

5 Y. H. Guan, J. Ma, X. C. Li, J. Y. Fang and L. W. Chen, Environ. Sci. Technol., 2011, 45, 9308-9314.

6 H. Hori, M. Murayama, N. Inoue, K. Ishida and S. Kutsuna, Catal. Today, 2010, 151, 131-136.

7 J. Chen, N. Gao, X. Lu, M. Xia, Z. Gu, C. Jiang and Q. Wang, RSC Adv., 2016, 6, 100056-100062.

8 Y. C. Chou, S. L. Lo, J. Kuo and C. J. Yeh, J. Hazard. Mater., 2015, 284, 83-91.

9 K. F. Chen, Y. C. Chang and K. Y. Liu, $R S C A d v$., 2016, 6, 75578-75587.

10 L. W. Matzek and K. E. Carter, Chemosphere, 2016, 151, 178188.

11 H. Li, J. Wan, Y. Ma, Y. Wang and M. Huang, Chem. Eng. J., 2014, 237, 487-496.

12 P. Avetta, A. Pensato, M. Minella, M. Malandrino, V. Maurino, C. Minero, K. Hanna and D. Vione, Environ. Sci. Technol., 2015, 49, 1043-1050.

13 Y. F. Rao, L. Qu, H. Yang and W. Chu, J. Hazard. Mater., 2014, 268, 23-32.

14 J. Yan, M. Lei, L. Zhu, M. N. Anjum, J. Zou and H. Tang, J. Hazard. Mater., 2011, 186, 1398-1404.

15 G. Ayoub and A. Ghauch, Chem. Eng. J., 2014, 256, 280-292.

16 X. Ruan, X. Gu, S. Lu, Z. Qiu and Q. Sui, Environ. Technol., 2015, 36, 1389-1397.

17 J. Yan, W. Gao, M. Dong, L. Han, L. Qian, C. P. Nathanail and M. Chen, Chem. Eng. J., 2016, 295, 309-316.

18 M. Feng, R. Qu, X. Zhang, P. Sun, Y. Sui, L. Wang and Z. Wang, Water Res., 2015, 85, 1-10.

19 K. W. Jung, B. H. Choi, T. U. Jeong and K. H. Ahn, Bioresour. Technol., 2016, 220, 672-676.

20 P. Sun, C. Hui, R. A. Khan, J. Du, Q. Zhang and Y. H. Zhao, Sci. Rep., 2015, 5, 12638.

21 A. Zielinska and P. Oleszczuk, Bioresour. Technol., 2015, 192, 618-626.

22 S. Muhammad, P. R. Shukla, M. O. Tade and S. Wang, J. Hazard. Mater., 2012, 215, 183-190.

23 T. Zeng, X. Zhang, S. Wang, H. Niu and Y. Cai, Environ. Sci. Technol., 2015, 49, 2350-2357.

24 T. Chen, Z. Zhou, S. Xu, H. Wang and W. Lu, Bioresour. Technol., 2015, 190, 388-394.

25 W. Zhang, S. Mao, H. Chen, L. Huang and R. Qiu, Bioresour. Technol., 2013, 147, 545-552.

26 T. Chen, Z. Y. Zhou, R. Han, R. H. Meng, H. T. Wang and W. J. Lu, Chemosphere, 2015, 134, 286-293.

27 H. Lu, W. Zhang, Y. Yang, X. Huang, S. Wang and R. Qiu, Water Res., 2012, 46, 854-862.

28 J. Zhang and Q. Wang, J. Cleaner Prod., 2016, 112, 3927-3934. 29 L. Peng, Y. Ren, J. Gu, P. Qin, Q. Zeng, J. Shao, M. Lei and L. Chai, Environ. Sci. Pollut. Res., 2014, 21, 7631-7640.

30 W. Zhang, J. Zheng, P. Zheng and R. Qiu, Chemosphere, 2015, 134, 438-445. 
31 X. Zhang, M. Hua, L. Lv and B. Pan, Sci. Rep., 2015, 5, 8253. 32 H. Li, J. Wan, Y. Ma, Y. Wang and Z. Guan, RSC Adv., 2015, 5, 99935-99943.

33 A. Zielinska, P. Oleszczuk, B. Charmas, J. SkubiszewskaZieba and S. Pasieczna-Patkowska, J. Anal. Appl. Pyrolysis, 2015, 112, 201-213.

34 H. Li, J. Wan, Y. Ma, M. Huang, Y. Wang and Y. Chen, Chem. Eng. J., 2014, 250, 137-147.

35 H. Wu, X. Che, Z. Ding, X. Hu, A. E. Creamer, H. Chen and B. Gao, Environ. Sci. Pollut. Res., 2016, 23, 1905-1915.

36 D. Mohan, P. Singh, A. Sarswat, P. H. Steele and C. U. Pittman Jr, J. Colloid Interface Sci., 2015, 448, 238-250.

37 P. Shen, H. T. Zhang, H. Liu, J. Y. Xin, L. F. Fei, X. G. Luo, R. Z. Ma and S. J. Zhang, J. Mater. Chem. A, 2015, 3, 34563464.

38 L. J. Leng, X. Z. Yuan, H. J. Huang, H. Wang, Z. B. Wu, L. H. Fu, X. Peng, X. H. Chen and G. M. Zeng, Fuel Process. Technol., 2015, 129, 8-14.

39 P. Devi and A. K. Saroha, Chem. Eng. J., 2015, 271, 195-203. 40 L. Qin, Z. Li, Z. Xu, X. Guo and G. Zhang, Appl. Catal., B, 2015, 179, 500-508.

41 J. Yang, Y. Zhao, S. Ma, B. Zhu, J. Zhang and C. Zheng, Environ. Sci. Technol., 2016, 50, 12040-12047.
$42 \mathrm{X} . \mathrm{Hu}, \mathrm{Z}$. Ding, A. R. Zimmerman, S. Wang and B. Gao, Water Res., 2015, 68, 206-216.

43 F. Xiao, W. Li, L. Fang and D. Wang, J. Hazard. Mater., 2016, 308, 11-20.

44 J. Zhou, H. Song, L. Ma and X. Chen, RSC Adv., 2011, 1, 782791.

45 C. Sun, R. Zhou, E. Jianan, J. Sun, Y. Su and H. Ren, RSC Adv., 2016, 6, 10633-10640.

46 T. Yamashita and P. Hayes, Appl. Surf. Sci., 2009, 255, 8194. 47 Y. Leng, W. Guo, X. Shi, Y. Li and L. Xing, Ind. Eng. Chem. Res., 2013, 52, 13607-13612.

48 Z. Li, Q. Yang, Y. Zhong, X. Li, L. Zhou, X. Li and G. Zeng, RSC Adv., 2016, 6, 987-994.

49 S. H. Yuan, P. Liao and A. N. Alshawabkeh, Environ. Sci. Technol., 2014, 48, 656-663.

50 K. Y. A. Lin, H. A. Chang and C. J. Hsu, RSC Adv., 2015, 5, 32520-32530.

51 M. Stoyanova, I. Slavova, S. Christoskova and V. Ivanova, Appl. Catal., A, 2014, 476, 121-132.

52 T. Zhou, X. Zou, J. Mao and X. Wu, Appl. Catal., B, 2016, 185, 31-41.

53 S. Naim and A. Ghauch, Chem. Eng. J., 2016, 288, 276-288.

54 M. Nie, Y. Yang, Z. Zhang, C. Yan, X. Wang, H. Li and W. Dong, Chem. Eng. J., 2014, 246, 373-382. 